\title{
Physician's referral patterns in a non-academic multispecialty group
}

\author{
John Wang ${ }^{1}$ and Larry Kravitz ${ }^{2 *}$ \\ ${ }^{1}$ Medical student, UT Southwestern Medical Center, USA \\ ${ }^{2}$ Family and Community Medicine, UT Southwestern Medical Center, USA
}

\section{Introduction}

Physician shortages have been a healthcare problem for several years. According to a 2018 study done by the Association of American Medical Colleges [1], there could be a shortage of up to 120,000 physicians in the United States by 2030, including up to 49,300 primary care physicians and 73,700 specialists. Considering there were 1,045,000 physicians estimated in the United States in 2013, this represents a need to increase by about $10 \%$.

In spite of this, in some areas, particularly large urban populations, there is a large abundance of specialists and subspecialists. Not only is there competition to obtain adequate referrals of patients, but there is turf overlap, where multiple specialties vie for care of the same medical problems.

During medical school, not much is taught about the practicalities of practice, such as the mechanics of effectively referring patients through the health care system nor on positioning oneself as a specialist in the system to obtain adequate access to appropriate patients. Physician referrals have been shown to affect many aspects of patient care, including cost and quality [2]. Previous studies have shown that individual physicians have marked variations in referral rates, which would suggest there is a lot of heterogeneity not only in the threshold to refer, but also which physicians will receive referrals [3-10]. A Harvard study in 2012 [11] surveyed 616 physicians who were members of an academic physicians' organization and found that $66 \%$ of PCPs referred to their "professional network" colleagues, and medical and surgical specialists referred to $49 \%$ and $52 \%$ to those in their network. This is unsurprising, because of convenience and financial advantage to in-house referrals. The Harvard study also found that medical specialists were less likely than PCPs to cite ease of communication with colleagues, and both medical and surgical specialists were less likely than PCPs to cite "shares my medical record system" as a reason to refer. However, this study is limited to a large academic organization. In medical school, referral patterns tend to be already established within the close nit academic center. Part of this is likely because in academic programs, there are a plethora of subspecialists and disease specific clinics. All this leads to a lack of experience of new physicians graduating into a private medical community without a plan or sophistication in directing patients for care among colleagues.

\section{Methodology}

This study attempts to gain some insight into how private practice physicians choose referrals. We surveyed physicians that are a part of Austin Regional Clinic, a multispecialty group that focuses on primary care and has 21 specialties. The anonymous surveys were sent out as

a Google Forms link (https://www.google.com/forms/about/) via email to all of the physicians in the group. Of the 324 recipients, 100 physicians responded to the survey, yielding a $31 \%$ response rate. The first half of the survey included questions relevant to this study, and the second half were questions collecting experience on referrals to specific physicians in the community. This study will only discuss the first half of the survey.

The survey was designed to allow physicians to rate how important thirteen different factors were in deciding which specialist a physician would refer to. The factors include:

1. their office is close to the patient's home

2. the specialist trained at an institution that trains good physicians

3. the specialist's focus is the specific disease of the patient

4. personally knowing the specialist very well

5. patients have told the physician that they like the specialist

6. they have good outcomes with the physician's patients

7. colleagues have said good things about the specialist

8. the specialist has communicated well with the referring physician in the past

9. the specialist has advertised to referring physician's office

10. the specialist is part of the referring physician's group's practice

11. how accessible is it for patients to get a prompt appointment

12. the referring physician went to a talk given by the specialist and it was well done

13. the specialist is well known for his/her leadership and/or community service.

The physicians were asked to rate the importance of each factor between 5 categories: (1) This is the most important factor in all instances, (2) This is more important than most other factors, (3) This is important but not as important as other factors, (4) All other things being equal, I would consider this factor, and (5) I do not consider

*Correspondence to: Larry Kravitz, MD, affiliate faculty, Family and Community Medicine, UT Southwestern Medical Center, USA, Tel: 512-338-8838; E-mail: lkravitz.md@gmail.com

Received: October 05, 2018; Accepted: October 22, 2018; Published: October 25,2018 
this at all. Results were converted to numerical scores from 1-5, with 5 being the best rating (reverse order of aforementioned list.) A mean and standard deviation were calculated using Microsoft Excel.

\section{Results}

The only two factors with mean scores of 4 and above were (1) patient outcomes (mean=4.47; $\mathrm{sd}=0.64$ ) and (2) specialist focus is the specific disease of the patient (mean $=4.00$; $s d=0.88$ ). Six factors had mean scores between 3 and 4: communication ( mean $=3.76$; sd $=0.79$ ), patients giving good reports about the specialist (mean $=3.71$; $\mathrm{sd}=0.80$ ), accessibility for appointment (mean $=3.74$; $\mathrm{sd}=0.77$ ), reputation among colleagues (mean $=3.55 ; \mathrm{sd}=0.80$ ), being part of the referring physician's practice (mean $=3.51$; sd $=0.84$ ), and having a personal acquaintance with the specialist $(m e a n=3.24 ; s d=1.00$.) Three factors scored means between 2 and 3: specialist location being close to the patient (mean $=2.95 ; \mathrm{sd}=0.87$ ), reputation of the specialist institutional training (mean=2.07; $\mathrm{sd}=1.02$ ), and having attended a talk by the specialist (mean=2.02; sd=1.00). The two factors scoring below a 2 included leadership/community service (mean $=1.86 ; \mathrm{sd}=0.96)$ and specialist having advertised to the referring doctor $($ mean $=1.45$; $\mathrm{sd}=0.62$ )

Table 1 shows the results of the survey, with the means and standard deviations of each factor score from 1-5. The factors were sorted into one of three categories: patient factors, physician's reputation, and experience with specialist. The patient factors included patient's location, patient's disease, patient's outcomes, and accessibility for appointment. Physician's reputation included their institution, their reputation among colleagues, and their reputation among patients. The experience with specialists group included personal acquaintance with the physician, specialist being good at communication, specialist having advertised at the office, the specialist being part of their practice, the specialist having spoke at a talk, and the specialist's leadership and community service. Patient factors scored the highest with a mean of $3.79(\mathrm{sd}=0.55)$, with physician's reputation second at $3.11(\mathrm{sd}=0.74)$, and the experience with specialist last with $2.64(\mathrm{sd}=0.89)$ (Figure 1).

Table 1. Results of the survey

\begin{tabular}{|c|c|c|c|c|c|c|c|c|c|c|c|c|c|}
\hline \multirow[t]{2}{*}{ Category } & \multicolumn{4}{|c|}{ Patient factors } & \multicolumn{3}{|c|}{ Physician's Reputation } & \multicolumn{6}{|c|}{ Experience with Specialist } \\
\hline & $\begin{array}{l}\text { Patient's } \\
\text { location }\end{array}$ & $\begin{array}{l}\text { Patient's } \\
\text { disease }\end{array}$ & $\begin{array}{l}\text { Patient's } \\
\text { outcomes }\end{array}$ & $\begin{array}{l}\text { Accessibility } \\
\text { for } \\
\text { appointment }\end{array}$ & Institution & $\begin{array}{l}\text { Reputation } \\
\text { among } \\
\text { colleagues }\end{array}$ & $\begin{array}{c}\text { Reputation } \\
\text { among } \\
\text { patients }\end{array}$ & $\begin{array}{c}\text { Personal } \\
\text { acquaintance } \\
\text { with } \\
\text { physician }\end{array}$ & $\begin{array}{c}\text { Specialist } \\
\text { is good at } \\
\text { communication }\end{array}$ & \begin{tabular}{|c|}
$\begin{array}{c}\text { Specialist } \\
\text { has }\end{array}$ \\
advertised \\
at office
\end{tabular} & $\begin{array}{l}\text { Specialist } \\
\text { is part } \\
\text { of my } \\
\text { practice }\end{array}$ & $\begin{array}{l}\text { Attended } \\
\text { talk by } \\
\text { specialist }\end{array}$ & $\begin{array}{c}\text { Leadership/ } \\
\text { community } \\
\text { service }\end{array}$ \\
\hline Mean & 2.95 & 4 & 4.47 & 3.74 & 2.07 & 3.55 & 3.71 & 3.24 & 3.76 & 1.45 & 3.51 & 2.02 & 1.86 \\
\hline $\begin{array}{l}\text { Standard } \\
\text { deviation }\end{array}$ & 0.87 & 0.88 & 0.64 & 0.77 & 1.02 & 0.8 & 0.8 & 1 & 0.79 & 0.62 & 0.84 & 1 & 0.96 \\
\hline $\begin{array}{l}\text { Category } \\
\text { Mean }\end{array}$ & \multicolumn{4}{|c|}{3.79} & \multicolumn{3}{|c|}{3.11} & \multicolumn{6}{|c|}{2.64} \\
\hline $\begin{array}{l}\text { Category } \\
\text { Standard } \\
\text { deviation }\end{array}$ & \multicolumn{4}{|c|}{0.55} & \multicolumn{3}{|c|}{0.74} & \multicolumn{6}{|c|}{0.89} \\
\hline
\end{tabular}

\section{Mean Scores for Factors Impacting Referrals}

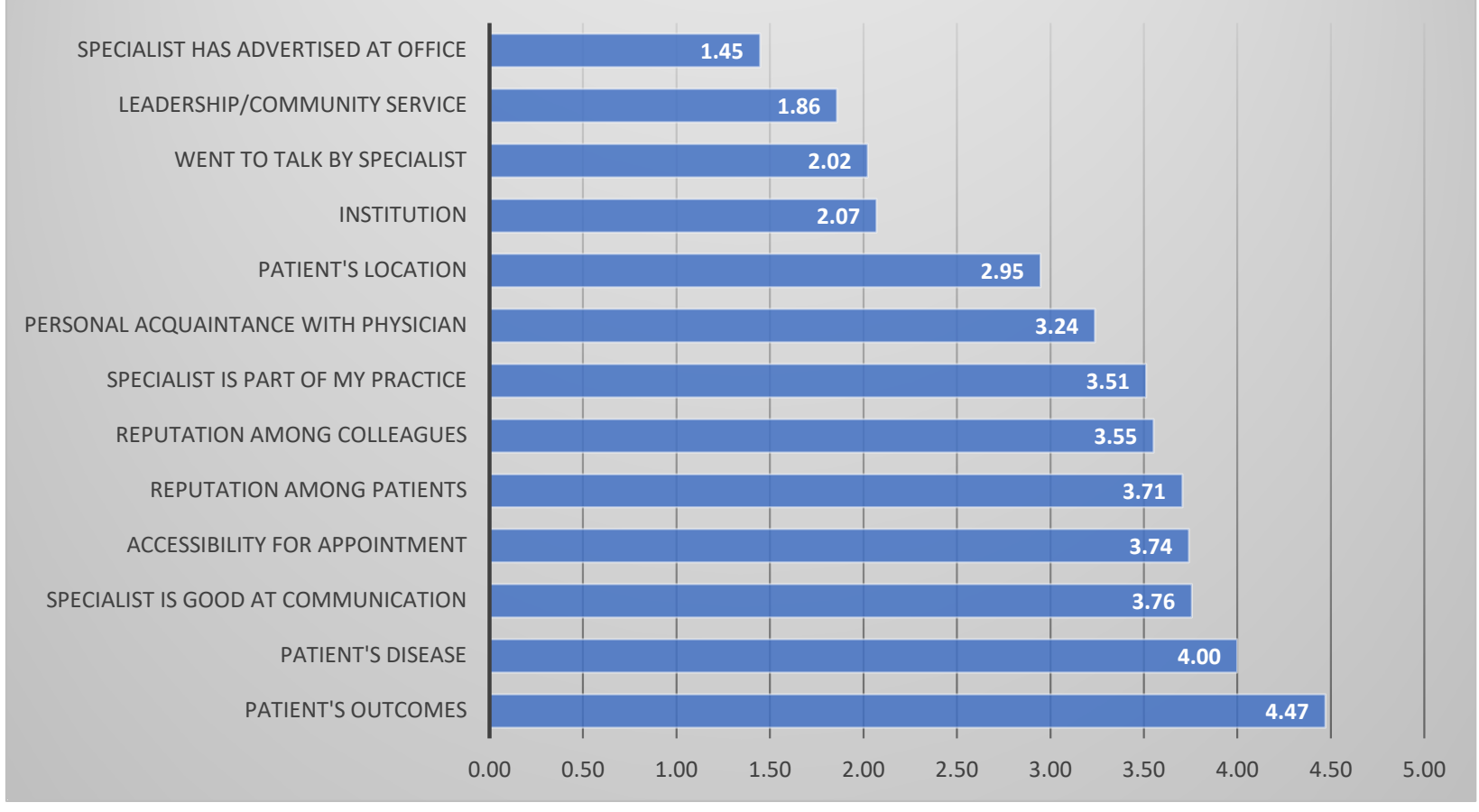

Figure 1. Mean Scores for Factors Impacting Referrals 


\section{Conclusions}

It is apparent that patient care is of utmost importance when it comes to choosing specialists in this group. Patient factors achieved the highest importance, with the lowest in the group arguably being the one that least affects outcomes (patient's location), and the highest being patient's outcomes. The relatively low standard deviation in the category of patient's factors, and especially regarding patient's outcomes, shows that this was a very common viewpoint. The reputation of the specialist among patients was more important to physicians than the reputation among their own colleagues. The physician's previous experience with how the specialist communicates is also an important part of clinical care.

Although surprisingly not higher in the hierarchy of decisionmaking, physicians strongly consider whether the specialist is part of their practice. There are likely multiple reasons for this. Internal referral likely improves the financial stability of the group. Also, the group may have a rigorous peer review process insures that their specialists are held to a high standard. Access to the appointment process may be easier within a large group. Specialist in large groups share medical records, improving the transfer of care process. And direct communication within a large group between specialist and primary care physicians may be easier to facilitate. They may work in the same office, share secure email, or share internal telephone access. They become familiar at department meetings and group annual and social meetings. Even support staff play an important role here, securing better transfer of care and access when working with their coworkers. Financially, management within a group can effectively correct care glitches and disruption promptly within a group, and there is little control when problems exist in an external specialist's office. Given that there are so many advantages to the use of internal specialists, it is surprising that this did not receive higher ratings. This survey in a private large medical group contrasts with the Harvard study in a more academic setting. Although the studies are not easily comparable, the academic setting seem to engender more support for the importance of in-house referrals.

To a medical student about to engage in the specialist residency application process, it is interesting to see how relatively unimportant the training institution seems to be in obtaining future referrals (professional behavior after residency seems more critical). A score of 2.07 aligns with "all other things being equal, I would consider this." Within any given specialty, there are probably many programs will train a competent specialist; it seems that physicians in large community practice agree with this sentiment. For a medical student, other factors may be more important in choosing residencies - access to fellowships, location preferences, and immediate financial considerations.

Specialists who are new in practice must choose their strategy to obtain a sustainable referral base. Our study aims at giving insight for specialists to understand the priorities of their referral base. Highly valued areas like good outcomes and patient feedback will just take time. Having a very specific disease focus will bring in patients, assuming there is an adequate occurrence of that disease in the specialist catchment area. Accessibility should be an advantage to the new physician, and the new specialist should prioritize thorough communication with the primary care physicians right from the outset. Perhaps no other single individual action is more highly valued by the specialist future sustainable referral base.

\section{References}

1. https://news.aamc.org/pressreleases/article/workforce_report_shortage_04112018/

2. Glenn JK, Lawler FH, Hoerl MS (1987) Physician referrals in a competitive environment. An estimate of the economic impact of a referral. JAMA 258: 1920-1923.

3. Boulware LE, Troll MU, Jaar BG, Myers DI, Powe NR (2006) Identification and referral of patients with progressive CKD: a national study. Am J Kidney Dis 48: $192-$ 204.

4. Starfield B, Forrest CB, Nutting PA, von Schrader S (2002) Variability in physician referral decisions. J Am Board Fam Pract 15: 473-80.

5. Scott JR, Wong E, Sowerby LJ (2015) Evaluating the referral preferences and consultation requests of primary care physicians with otolaryngology - head and neck surgery. J Otolaryngol Head Neck Surg 44: 57. [Crossref]

6. Fitzgerald A, de Coster C, McMillan S, Naden R, Armstrong F, et al. (2011) Relative urgency for referral from primary care to rheumatologists: the Priority Referral Score. Arthritis Care Res (Hoboken) 63: 231-239. [Crossref]

7. Donelan K, Rao SR, Rogers RS, Mailhot JR, Galvin R (2010) Experience with health coach-mediated physician referral in an employed insured population. $J$ Gen Intern Med 25:1071-1077. [Crossref]

8. Tseng E, Wang NY, Clark JM, Appel LJ, Bennett WL (2015) Role of PCP referral and weight loss in the Hopkins POWER trial. Prev Med Rep 2: 968-972. [Crossref]

9. Cohen SM, Kim J, Roy N, Courey M (2014) Factors influencing referral of patients with voice disorders from primary care to otolaryngology. Laryngoscope 124: 214-220. [Crossref]

10. Cornell E, Chandhok L, Rubin K (2015) Implementation of referral guidelines at the interface between pediatric primary and subspecialty care. Healthc (Amst) 3: 74-79. [Crossref]

11. Barnett ML, Keating NL, Christakis NA, Malley AJO, Landon BE (2012) Reasons for Choice of Referral Physician Among Primary Care and Specialist Physicians. J Gen Inter Med 27: 506-512.

Copyright: (C2018 Wang J. This is an open-access article distributed under the terms of the Creative Commons Attribution License, which permits unrestricted use, distribution, and reproduction in any medium, provided the original author and source are credited. 